\title{
Factors behind burnout increase in medical students. Are the criteria so important?
}

Fatores por trás do burnout crescente em estudantes de medicina. Os critérios são tão importantes?

\begin{tabular}{|c|c|}
\hline \multirow{2}{*}{$\begin{array}{l}\text { Thais Campelo Bedê Vale' } \\
\text { José Hícaro Hellano Gonçalves Lima Paiva' }\end{array}$} & |thaisbede1@gmail.com \\
\hline & hellanohicaro@gmail.com \\
\hline Vitória Nunes Medeiros ${ }^{1}$ (1) & vitorianunes21@gmail.com \\
\hline Pedro Ítalo Oliveira Gomes ${ }^{2}$ (c) & pedroitalo_oli@hotmail.com \\
\hline n Cryslen Bernardo Bezerra' & hellen.cryslen@aluno.uece.br \\
\hline a Paschoalette Rodrig & tatiana.bachur@uece.br \\
\hline & rocketm \\
\hline
\end{tabular}

\section{ABSTRACT}

Introduction: Medical students' mental health has been a concern to the scientific community, especially as a result of the epidemic of mental comorbidities that have become commonplace among the various social groups in modern society.

Objectives: To evaluate the prevalence of Burnout among first- to fourth-year medical students and compare different criteria to define the syndrome.

Methods: A total of 511 students from three universities in Brazil answered validated instruments to assess burnout (The Maslach Burnout Inventory) and quality of life (WHOQOL-BREF), and a questionnaire prepared by the authors to assess sociodemographic data

Results: There was a prevalence of $31.1 \%$ of three-dimensional burnout, $37 \%$ of two-dimensional burnout and $44,8 \%$ of one-dimensional burnout. There were worse levels of emotional exhaustion among students with two-dimensional burnout, compared to those with only one-dimensional criterion, and worse levels of depersonalization among students with three-dimensional burnout, compared to those with two-dimensional criterion only. The same assessed variables showed correlation with all three criteria. Considering the four domains of quality of life - psychological, physical, environment and social relationships, the psychological and physical domains were the ones that correlated the most to all three aspects of the threedimensional criteria. Emotional exhaustion was the dimension with the strongest association with three of the four quality of life domains.

Conclusions: We question whether the three-dimensional criterion should really be the gold standard to define Burnout.

Keywords: Burnout; Medical Students; Diagnostic.

\section{RESUMO}

Introdução: A saúde mental dos estudantes de medicina tem sido uma preocupação para a comunidade científica, especialmente como resultado da epidemia de comorbidades mentais que se tornaram comuns entre os vários grupos sociais da sociedade moderna.

Objetivos: Este estudo teve como objetivos avaliar a prevalência de burnout em estudantes do primeiro ao quarto ano de um curso de Medicina e comparar as diferentes classificações de critério diagnóstico da síndrome.

Métodos: Um total de 511 estudantes de três universidades brasileiras responderam a dois instrumentos validados para avaliar burnout e qualidade de vida, e a um questionário elaborado pelos autores para avaliar dados sociodemográficos e hábitos.

Resultados: Houve prevalência de 31,1\% de burnout tridimensional, 37\% de burnout bidimensional e 44,8\% de burnout unidimensional. Constatou-se um maior nível de exaustão no grupo com burnout bidimensional, em comparação ao grupo unidimensional, e verificou-se um maior nível de cinismo naqueles com burnout tridimensional, em comparação ao bidimensional. As variáveis que apresentaram correlação com a síndrome foram as mesmas nos três critérios analisados. Os domínios psicológico e físico foram os mais afetados na qualidade de vida dos escolares com burnout. A exaustão emocional foi a dimensão que apresentou correlações mais fortes com três dos quatro domínios analisados no instrumento WHOQOL-BREF.

Conclusão: Observaram-se prejuízos nas diversas áreas relacionadas à qualidade de vida dos alunos. Questionamos se o uso do Maslach Burnout Inventory, por meio da abordagem tridimensional, realmente é o critério ideal a ser utilizado na triagem do burnout.

Palavras-chave: Esgotamento Profissional; Estudantes de Medicina; Diagnóstico.

\footnotetext{
${ }^{1}$ Universidade Estadual do Ceará, Fortaleza, Ceará, Brazil.

${ }^{2}$ Universidade Federal do Cariri, Fortaleza, Ceará, Brazil.

Chief Editor: Daniela Chiesa

Associate Editor: Izabel Cristina Meister Martins Coelho
}

Received on 06/11/20; Accepted on 02/08/21.

Evaluated by the double blind review process. 


\section{INTRODUCTION}

Medical students' mental health has been a concern to the scientific community, especially as a result of the epidemic of mental comorbidities that have become commonplace among the various social groups in modern society'. In addition to medical school-related burdens, many demands and responsibilities are placed on these students, since this profession is focused on patient care, and it has minimal tolerance for errors ${ }^{2}$.

The education period is a complex and laborious process, characterized by several stressors such as high school performance requirements, reduced leisure time, high study load, high amount of information to assimilate, among others ${ }^{3,4}$. Thus, the development of nonpsychotic psychiatric disorders e.g., depression, anxiety, and burnout - are commonly found in this population ${ }^{5,6}$.

An important condition associated with the exhaustive nature of medical education is burnout, a concept introduced by psychologist Herbert Freudenberger in 1974. He defined burnout as "a progressive loss of idealism, energy, and purpose experienced by people in the helping professions as a result of the conditions of their work"7.

The burnout syndrome is associated with varying degrees of emotional exhaustion, depersonalization of the physician-patient process, loss of idealism and low sense of self-fulfillment ${ }^{8}$. Thus, to diagnose it, changes in dimensions related to emotional exhaustion, cynicism, and professional disbelief/low efficacy should be considered. Exhaustion, the main manifestation of burnout, is described as physical and emotional stress caused by high academic demand. The dimension of cynicism consists in the student's withdrawal from learning, which can be a form of self-defense. Finally, inefficiency reflects the student's feeling of unhappiness and dissatisfaction with their academic knowledge?.

The first instrument created for the assessment of burnout, and the most used to date, is the Maslach Burnout Inventory (MBI), initially developed to assess the syndrome in human service professionals using the three-dimensional criterion ${ }^{9}$. From the emergence of studies describing burnout in other areas, there have been variations of the $\mathrm{MBI}$, such as the Maslach Burnout Inventory-Student Survey (MBI-SS), an adaptation made to assess the syndrome in students ${ }^{10}$, validated in Brazil by Carlotto ${ }^{11}$.

However, there are controversies in the literature regarding the diagnostic criteria. Some studies have chosen a two-dimensional approach, considering only emotional exhaustion and cynicism, such as the Oldenburg Burnout Inventory (OLBI), suggesting that ineffectiveness would be a personality pattern, rather than a component of the syndrome ${ }^{12}$.
In addition, other studies have chosen a one-dimensional criterion based only on emotional exhaustion, such as the Copenhagen Burnout Inventory (CBI), which follows a line of thought similar to that of OLBI: cynicism and low personal achievement would be different phenomena and should be analyzed and studied separately ${ }^{13}$.

This study aimed to investigate the prevalence of burnout among medical students from three universities in Brazil, evaluating and suggesting ideas about which diagnostic criteria of the syndrome can contribute to the screening of the condition and an earlier intervention.

\section{METHODS}

\section{Type of study, data collection, population, and sample}

This is a multicenter, analytical, cross-sectional study conducted in three northeastern Brazilian universities. Data collection was performed using two scales and a questionnaire in students from the first to the fourth year of medical school. The final sample consisted of 511 undergraduate medical students, distributed per year of medical school: 111 from the first year, 174 from the second year, 138 from the third year, and 88 from the fourth year.

The study sample represents around $50 \%$ of the total of students from the three universities. The rest of the students were excluded for one of two reasons: the students either chose not to participate or they answered incorrectly (e.g. left blank answers).

During the data collection period, at least one of the researchers was a student in each university. We sent emails to the students explaining the research and, subsequently, they were approached in person, after or in-between classes, to fill out the questionnaires. The data were collected between September and October of 2018.

When the study results were analyzed and showed to be a matter of concern, the students could not be approached individually because of the anonymity, but the faculty members were informed about the results, so that institutional measures could be taken.

\section{Data collection instruments}

Two internationally validated scales and one evaluative questionnaire prepared by the authors, which included complementary data to the scales, were used. The questionnaire consists of objective questions about demographic and academic information, sleep habits, need for psychotherapeutic follow-up, perception of the emotional support offered by the faculty, smoking status and use of psychoactive and illicit drugs.

The Maslach Burnout Inventory-Student Survey (MBISS) is a validated instrument used by several studies to screen for burnout ${ }^{11}$. The items evaluate three dimensions: emotional 
exhaustion, cynicism, and academic efficacy. Low scores for academic efficacy (Low: 22 or lower; Moderate: 23-27; High: 28 or higher) and high scores for emotional exhaustion (Low: 0-9; Moderate: 10-14; High: 15 or higher) and cynicism/ depersonalization (Low: 0-1; Moderate: 2-6; High: 7 or higher) are indicative of burnout, according to the three-dimensional criterion, the most frequently adopted in studies. The twodimensional criterion involves high scores for emotional exhaustion and cynicism. The one-dimensional criterion involves only high scores for emotional exhaustion.

The WHOQOL-BREF instrument is used to assess quality of life, and there have been studies that validated its use in medical students ${ }^{14}$. The instrument addresses four domains: physical, psychological, social relationships, and environment. The score for each domain is obtained from an average score, according to the number of questions in the domain.

\section{Data analysis}

Categorical data were expressed as absolute counts with frequency and percentages and were compared by chisquare test. All quantitative variables were tested for normal distribution using the Kolmogorov-Smirnov test. Variables with normal distribution were presented as mean \pm standard deviation and non-normal data were shown as median and interquartile range. Student's t-test, one-way analysis of variance (ANOVA) with Tukey post-test, or the Kruskal-Wallis test with Dunn's post-test were used to compare means/ medians of continuous variables accordingly to the distribution of data between the groups.

Correlations were evaluated by Pearson's correlation. Additionally, univariate logistic regression was used to assess the association between variables with the presence of burnout. All analyses were performed using IBM SPSS Statistics for MAC OSX, version 23.0 (IBM, USA).

\section{Ethical aspects}

The project was approved by the Research Ethics Committee of Universidade Estadual do Ceará. Consent was requested from participants through a signed Informed Consent Form and anonymity was ensured.

\section{RESULTS}

A sample of 511 students attending the first to the eighth semesters of medical school participated in the research, $58 \%$ of which were males. Students in the basic cycle of medical school (first and second years) represented $56 \%$ of the sample, while the remainder were in the clinical cycle. About $90 \%$ of the sample was in the age group between 17 and 24 years. Table 1 shows the general sociodemographic data and according to the participants' gender.
Table 1. Sociodemographic data

\begin{tabular}{|c|c|c|c|}
\hline VARIABLES & $\begin{array}{c}\text { ALL } \\
(n=511)\end{array}$ & $\begin{array}{l}\text { WOMEN } \\
(n=216)\end{array}$ & $\begin{array}{c}\text { MEN } \\
(n=295)\end{array}$ \\
\hline \multicolumn{4}{|l|}{ Age } \\
\hline 17 to 20 years old & $229(44.81 \%)$ & $96(44.4 \%)$ & $133(45.1 \%)$ \\
\hline 21 to 24 years old & $233(45.59 \%)$ & 99 (45.8\%) & $134(45.4 \%)$ \\
\hline Over 25 years old & $49(9.58 \%)$ & $21(9.7 \%)$ & $28(9.5 \%)$ \\
\hline \multicolumn{4}{|l|}{ Year of Medical School } \\
\hline First year & $111(21.72 \%)$ & $45(20.8 \%)$ & $66(22.4 \%)$ \\
\hline Second year & $174(34.05 \%)$ & 71 (32.9\%) & $103(34.9 \%)$ \\
\hline Third year & $138(27 \%)$ & $69(31.9 \%)$ & $69(23.4 \%)$ \\
\hline Fourth year & $88(17.22 \%)$ & $31(14.4 \%)$ & 57 (19.3\%) \\
\hline \multicolumn{4}{|l|}{ Hours of Sleep } \\
\hline 3 to 6 hours & $277(54.2 \%)$ & $120(55.6 \%)$ & $157(53.2 \%)$ \\
\hline Over 6 hours & $232(45.4 \%)$ & 96 (44.4\%) & $136(46.1 \%)$ \\
\hline Sleep medication use & $40(7.8 \%)$ & $20(9.3 \%)$ & $20(6.8 \%)$ \\
\hline \multicolumn{4}{|l|}{ Medication used } \\
\hline alprazolam & $4(0.78 \%)$ & $2(10 \%)$ & $2(11.1 \%)$ \\
\hline amitriptyline & $2(0.39 \%)$ & $1(5 \%)$ & $1(5.6 \%)$ \\
\hline clonazepam & $7(1.36 \%)$ & $3(15 \%)$ & $4(22.2 \%)$ \\
\hline zolpidem & $6(1.17 \%)$ & $3(15 \%)$ & $3(16.7 \%)$ \\
\hline others & $19(3.71 \%)$ & $11(55 \%)$ & $8(44.4 \%)$ \\
\hline Use of caffeine & $273(53.42 \%)$ & $117(54.2 \%)$ & $156(52.9 \%)$ \\
\hline \multicolumn{4}{|l|}{ Frequency } \\
\hline Less than 5 times a day & 237 (46.37\%) & $103(89.6 \%)$ & $134(80.2 \%)$ \\
\hline 5 to 10 times a day & $29(5.67 \%)$ & $12(10.4 \%)$ & $27(16.2 \%)$ \\
\hline Over 10 times a day & $6(1.17 \%)$ & $0(0.0 \%)$ & $6(3.6 \%)$ \\
\hline $\begin{array}{l}\text { Psychoactive } \\
\text { substance use }\end{array}$ & 153 (29.94\%) & $65(30.1 \%)$ & $88(29.8 \%)$ \\
\hline Energy drinks & $104(20.35 \%)$ & $52(75.4 \%)$ & $52(63.4 \%)$ \\
\hline Energy drinks + others & $10(1.95 \%)$ & $2(2.9 \%)$ & $8(9.8 \%)$ \\
\hline Ritalin & $10(1.95 \%)$ & $5(7.2 \%)$ & $5(6.1 \%)$ \\
\hline Others & $23(4.5 \%)$ & $9(13 \%)$ & $14(17.1 \%)$ \\
\hline Not answered & $4(0.78 \%)$ & $1(1.4 \%)$ & $3(3.7 \%)$ \\
\hline Illicit drug use & $91(17.8 \%)$ & $34(15.7 \%)$ & $57(19.3 \%)$ \\
\hline Smoker & $67(13.11 \%)$ & $23(10.6 \%)$ & $44(15.0 \%)$ \\
\hline \multicolumn{4}{|l|}{ When they started smoking } \\
\hline Before university & $36(7.04 \%)$ & $8(34.8 \%)$ & $28(63.6 \%)$ \\
\hline During university & $31(6.06 \%)$ & $15(65.2 \%)$ & $16(36.4 \%)$ \\
\hline $\begin{array}{l}\text { Increased smoking } \\
\text { during university }\end{array}$ & $18(3.52 \%)$ & $9(30 \%)$ & $9(15.5 \%)$ \\
\hline Exercise/physical activity & $269(52.64 \%)$ & $108(50 \%)$ & $161(54.6 \%)$ \\
\hline \multicolumn{4}{|c|}{ Exercise frequency per week } \\
\hline Less than 3 times & $113(22.11 \%)$ & 57 (50.9\%) & $56(33.5 \%)$ \\
\hline 3 to 5 times & $138(27 \%)$ & $48(42.9 \%)$ & 90 (53.9\%) \\
\hline Over 5 times & $28(5.47 \%)$ & $7(6.3 \%)$ & $21(12.6 \%)$ \\
\hline $\begin{array}{l}\text { Underwent } \\
\text { psychotherapy in } \\
\text { medical school }\end{array}$ & 147 (28.76\%) & $82(38.8 \%)$ & $65(22 \%)$ \\
\hline Emotional support & $50(9.78 \%)$ & $15(6.9 \%)$ & $35(11.9 \%)$ \\
\hline
\end{tabular}

Source: Prepared by the authors. 
Regarding the students' daily hours of sleep, it was found that $54 \%$ slept 3 to 6 hours per night, while $46 \%$ claimed to have more than 6 hours of sleep. Forty students (8\%) reported regular use of sleep medications, namely: alprazolam (11\%), amitriptyline (5\%), clonazepam (18\%), zolpidem (16\%), and others (50\%).

The use of psychoactive substances was reported by 153 students (30\%), and energy drinks showed a significant percentage (69\%). Of the sample studied, $18 \%$ and $13 \%$ reported drug use and smoking, respectively. Of the smokers, $46 \%$ started smoking during medical school. Twenty percent of the smokers considered that attending medical school stimulated the smoking habit.

A total of 174 students (29\%) stated they needed psychotherapeutic support at some point during medical school. The majority of students ( $90 \%)$ do not feel they receive enough emotional support from the faculty at their universities; among students with three-dimensional burnout, this number was $96.2 \%$, with a statistically significant difference $(p<0.05)$.

Table 2 shows the general aspects of burnout. It was found that $37 \%$ of students had a diagnosis of burnout according to the two-dimensional criterion, 31\% considering the three-dimensional criterion, and $44,8 \%$ considering the one-dimensional criterion. There was a higher level of cynicism/ depersonalization among the students with three-dimensional burnout compared to those with only the two-dimensional criterion, and a higher level of emotional exhaustion among students with only the two-dimensional burnout, compared to those with only the one-dimensional criterion.

Table 3 shows the correlation of burnout (one-, twoand three-dimensional) with other parameters. A statistical correlation was found between burnout and age, and students under 25 years old were the least affected. The syndrome is also more often present in the students who sleep less than 6 hours per night, those who needed psychotherapeutic follow-up in medical school, and those who needed medications to regulate their sleeping patterns. There was no statistically significant correlation between burnout and drug abuse, harmful alcohol use (i.e., moderate risk or worse), smoking, psychoactive substance use and year of medical school the students were attending (basic or clinical cycle).

Table 4 describes the correlation between the four quality of life domains and all three burnout aspects, according to the three-dimensional criterion. The physical and psychological domains were the most often related to all aspects of the syndrome. Emotional exhaustion was the aspect with the strongest correlations with almost all quality of life domains, except for the social relationships domain.

\section{DISCUSSION}

Considering the most traditional criterion adopted, the prevalence of $31.1 \%$ of three-dimensional burnout detected in the study population is high when compared to what was found in similar studies ${ }^{15,16}$. A Brazilian study conducted with students from the first to the sixth year and two studies conducted with students from the first to the fourth year of medical school - the

Table 2. General aspects of burnout

\section{Proportion of Burnout $(n=511)$}

Burnout

Three-dimensional Burnout

Two-dimensional Burnout

One-dimensional Burnout
$229(37 \%)$

159 (31\%)

$188(37 \%)$

$229(44.8 \%)$

Evaluation of burnout scores according to its presence

\begin{tabular}{|c|c|c|c|c|c|}
\hline VARIABLE & $\begin{array}{l}\text { Without } \\
\text { Burnout } \\
(n=323)\end{array}$ & $\begin{array}{l}\text { One-dimensional } \\
\text { burnout only }(n=41)\end{array}$ & $\begin{array}{l}\text { Two-dimensional burnout } \\
\text { only, except those with } \\
\text { three-dimensional burnout } \\
(n=29)\end{array}$ & $\begin{array}{l}\text { Three-dimensional } \\
\text { Burnout }(n=159)\end{array}$ & $\mathbf{P}$ \\
\hline \multicolumn{6}{|l|}{ Burnout Scores } \\
\hline Efficacy & $22 \pm 6.49$ & $26.98 \pm 3.14$ & $25.41 \pm 2.68$ & $15.09 \pm 4.23$ & $<0.001$ \\
\hline Cynicism & $4.23 \pm 3.82$ & $3.39 \pm 2,08$ & $11.03 \pm 4.47$ & $13.16 \pm 4.93$ & $<0.001$ \\
\hline Exhaustion & $12.3 \pm 5.54$ & $19.15 \pm 3.61$ & $22.69 \pm 4.18$ & $21.72 \pm 4.44$ & $<0.001^{*}$ \\
\hline $\begin{array}{l}\text { Sum (cynicism } \\
\text { and exhaustion) }\end{array}$ & $16.53 \pm 7.09$ & - & $33.72 \pm 7.09$ & $34.88 \pm 7.9$ & $<0.001^{*}$ \\
\hline
\end{tabular}

Caption: Data expressed as absolute counts and percentage in parentheses or as mean/standard deviation. Chi-square test for independence for categorical data and ANOVA for quantitative data were used; * $p<0.05$ except for "Two-dimensional Burnout" vs "Three-dimensional Burnout".

Source: Prepared by the authors. 
Table 3. Evaluation between clinical parameters for burnout development

\begin{tabular}{|c|c|c|c|c|c|c|c|c|c|c|}
\hline \multirow[t]{2}{*}{ VARIABLES } & \multirow{2}{*}{$\begin{array}{c}N=511 \\
N\end{array}$} & \multicolumn{3}{|c|}{$\begin{array}{l}\text { ONE-DIMENSIONAL } \\
\text { (229) }\end{array}$} & \multicolumn{3}{|c|}{$\begin{array}{l}\text { TWO-DIMENSIONAL } \\
(n=188)\end{array}$} & \multicolumn{3}{|c|}{$\begin{array}{l}\text { THREE-DIMENSIONAL } \\
(n=159)\end{array}$} \\
\hline & & O.R & $\mathrm{Cl}$ & $p$ & O.R & $\mathrm{Cl}$ & $p$ & O.R & $\mathrm{Cl}$ & $p$ \\
\hline Gender (female) & 216 & 1.361 & $0,955-1.939$ & 0.088 & 1.252 & $0.871-1.800$ & 0.225 & 1.195 & $0.819-1.744$ & 0.354 \\
\hline Age (under 25 years) & 462 & 0.444 & $0.233-0.847$ & 0.014 & 0.523 & $0.290-0.946$ & 0.032 & 0.517 & $0.285-0.940$ & 0.031 \\
\hline $\begin{array}{l}\text { Hours of Sleep (less than } 6 \\
\text { hours) }\end{array}$ & 278 & 1.882 & $1.322-2.679$ & 0.000 & 1.717 & $1.189-2.480$ & 0.004 & 1.789 & $1.217-2.631$ & 0.003 \\
\hline $\begin{array}{l}\text { Underwent psychotherapy } \\
\text { in medical school }\end{array}$ & 147 & 1.882 & $1.266-2.8$ & 0.002 & 1.75 & $1.184-2.588$ & 0.005 & 1.77 & $1.189-2.646$ & 0.005 \\
\hline Second-year students & 174 & 1.343 & $0.927-1.945$ & 0.119 & 1.286 & $0.890-1.889$ & 0.177 & 1.37 & $0.928-2.022$ & 0.114 \\
\hline Fourth-year students & 88 & 0.685 & $0.432-1.085$ & 0.107 & 0.816 & $0.502-1.327$ & 0.413 & 0.647 & $0.381-1.100$ & 0.108 \\
\hline Smoker & 67 & 0.84 & $0.502-1.405$ & 0.507 & 0.881 & $0.513-1.511$ & 0.645 & 0.931 & $0.531-1.630$ & 0.802 \\
\hline Sleep medication & 40 & 1.613 & $0.822-3.167$ & 0.165 & 2.493 & $1.295-4.798$ & 0.006 & 2.651 & $1.382-5.086$ & 0.003 \\
\hline Psychoactive substance use & 153 & 1.197 & $0.817-1.754$ & 0.356 & 1.114 & $0.754-1.647$ & 0.587 & 1.109 & $0.739-1.664$ & 0.618 \\
\hline $\begin{array}{l}\text { Harmful alcohol use } \\
\text { (moderate risk to probable } \\
\text { dependence - zones II, III, } \\
\text { and IV) }\end{array}$ & 79 & 1.001 & $0.619-1.621$ & 0.996 & 0.933 & $0.566-1.540$ & 0.787 & 0.96 & $0.570-1.616$ & 0.878 \\
\hline Drug use & 91 & 1.084 & $0.687-1.711$ & 0.729 & 1.154 & $0.725-1.837$ & 0.546 & 1.251 & $0.776-2.018$ & 0.358 \\
\hline
\end{tabular}

Caption: Data expressed as absolute counts and percentage in parentheses. Source: Prepared by the authors.

Table 4. Association between quality of life domains and Burnout

\begin{tabular}{lcccccc}
\hline & \multicolumn{3}{c}{ Association between quality of life domains and burnout aspects } \\
\cline { 2 - 7 } & \multicolumn{2}{c}{ Efficacy } & Cynicism & \multicolumn{2}{c}{ Exhaustion } \\
\cline { 2 - 7 } & $\mathbf{R}$ & $\mathbf{p}$ & $\mathbf{R}$ & $\mathbf{p}$ & $\mathbf{R}$ & $\mathbf{P}$ \\
\hline Physical domain & $0.411^{* *}$ & $<0.001$ & $-0.450^{* *}$ & $<0.001$ & $-0.531^{* *}$ & $<0.001$ \\
Psychological domain & $0.447^{* *}$ & $<0.001$ & $-0.474^{* *}$ & $<0.001$ & $-0.520^{* *}$ & $<0.001$ \\
Social relationships domain & $0.278^{* *}$ & $<0.001$ & $-0.292^{* *}$ & $<0.001$ & $-0.282^{* *}$ & $<0.001$ \\
Environment domain & $0.264^{* *}$ & $<0.001$ & $-0.275^{* *}$ & $<0.001$ & $-0.321^{* *}$ & $<0.001$ \\
\hline
\end{tabular}

Caption: Data expressed as median and interquartile range in parentheses.

** Pearson's R representing the strength of the association between quality of life domains with each burnout aspect.

Source: Prepared by the authors.

same period analyzed in the present study - showed prevalence rates of $10.3 \%{ }^{16}, 14.9 \%{ }^{15}$, and $26.4 \%{ }^{5}$ of the syndrome respectively, also considering the three-dimensional criterion.

In the international literature, a systematic review of the syndrome in medical students showed that burnout is very prevalent during medical school ${ }^{16}$. Large multicenter studies found that at least half of medical students are affected during this period ${ }^{17,18}$. This higher prevalence of burnout compared to that of the present study could be explained mainly by the criterion adopted to diagnose the syndrome, since studies that use the one-dimensional or two-dimensional criteria show a higher prevalence. Considering the two- and one-dimensional criterion for our study, we found prevalence rates of $37 \%$ and $44.8 \%$, respectively. Moreover, diverse cultural factors and individual characteristics of the students could also contribute to the development of the syndrome, as previously suggested ${ }^{19-22}$. Maslach (1993) has suggested that employees suffering from burnout first experience exhaustion, then depersonalization/ cynicism and reduced personal accomplishment. We compared three groups: the first one containing students who would fit only the one-dimensional criterion - those who only had emotion exhaustion, but not depersonalization or low academic efficacy; the second containing the students who would fit only the twodimensional criterion - those who did not have low academic efficacy but had emotional exhaustion and depersonalization - and the last containing those with three-dimensional burnout. Comparing the first and the second groups, we observed that there was a higher level of emotional exhaustion in the second group. Comparing the second and third groups, there was a higher level of cynicism in those with three-dimensional burnout. These data 
may be related to a possible evolution of burnout. High levels of emotional exhaustion may progress into attitudes of indifference and distancing in an attempt to minimize this exhaustion, leading to cynicism. This progression to cynicism can culminate in a sense of personal dissatisfaction, as losing activity motivation, which becomes a cause of discontent, leading to the perception of low academic efficacy. Thus, higher levels of cynicism, associated with emotional exhaustion, could lead to impaired academic performance, completing the classic burnout triad ${ }^{15}$.

Considering that the same studied variables showed correlation with all the criteria - one-, two- and threedimensional burnout, as shown in table 3, we question whether the use of the three-dimensional criterion, which is more classically described, would only delay the detection of the syndrome, leading to diagnosis at more advanced stages of the process. In addition to that, even though these findings could reinforce the traditional theory related to the syndrome, there is an important discussion in the literature regarding the right criterion to define burnout. As previously mentioned, some authors suggest that a two-factor model that includes only emotional exhaustion and depersonalization might be more appropriate for some reasons. Firstly, because personal accomplishment is differentially related to other organizational outcomes (e.g., job satisfaction and organizational commitment). Secondly, because it is perhaps more appropriately conceptualized as a personality trait or a coping resource rather than a burnout component ${ }^{12,23}$.

The same logic has been applied to depersonalization. The depersonalization process was described by Maslach as a form of distancing oneself, which professional groups develop to cope with stress. Taking that into consideration, it has been suggested that depersonalization should be analyzed along with other coping strategies and it should not be necessary to define the syndrome ${ }^{13}$.

In addition to the concerns over the three-factor structure of the $\mathrm{MBI}$, some authors criticize the fact that it focuses only on the affective components of emotional exhaustion. It has been suggested that the exhaustion component should include other aspects of exhaustion, including cognitive and physical exhaustion, in order to better capture the nature of exhaustion, which is experienced as a result of chronic work stress ${ }^{12}$. We correlated every aspect of the three-dimensional burnout with four domains of quality of life: physical, psychological, environment and social relations. We observed that the physical and psychological domains were the most often related to the three dimensions of the syndrome. Interestingly, there was a stronger association of the cynicism and low academic efficacy dimensions with the psychological domain, while emotional exhaustion showed a stronger association with the physical domain, followed by the psychological domain (Table 4). This could reinforce that exhaustion related to burnout is not only emotional, but also physical and it should be more directly addressed.

We also observed that the emotional exhaustion aspect showed stronger correlations with three of the four quality of life domains when compared to depersonalization and low academic efficacy: physical, psychological and environment (Table 4). This could reinforce the theory that emotional exhaustion should be considered the most important, if not the only component to define burnout.

This study has limitations. Because this is a cross-sectional study, it is not possible to define a cause and effect relationship; only associations can be demonstrated. Moreover, with the use of self-administered instruments, there is the possibility of social desirability bias and answer distortion. Moreover, as four instruments were applied, it is possible that part of the students may have rushed into answering some questions not to prolong the time to complete the questionnaires, which may have impaired the information accuracy.

\section{CONCLUSION}

Although the three-dimensional criterion is the only one that addresses the three aspects of burnout present in the Maslach Burnout Inventory, we question whether it should really be the gold standard to define Burnout or if that definition needs to be revised. It is possible that there is a greater advantage in using the two-dimensional or onedimensional syndrome criteria, not only to attain a more correct and current concept of the Burnout, but also as a way to screen for the condition and intervene earlier, before the students develop harmful coping mechanisms. In addition, using a standardized criterion for the syndrome would allow standardizing its diagnosis between different studies, allowing a better comparison between different populations.

\section{AUTHORS' CONTRIBUTION}

All authors contributed equally to the study.

\section{CONFLICTS OF INTEREST}

The authors report no conflicts of interest. The authors alone are responsible for the content and writing of this article.

\section{SOURCES OF FUNDING}

This research did not receive any specific grant from funding agencies in the public, commercial, or not-for-profit sectors.

\section{REFERENCES}

1. Organization WH. Depression and Other Common Mental Disorders Global Health Estimates. World Heal Organ. 2017;1-24. 
2. Harvey S, Laird B, Henderson M, Hotopf M. The mental health of healthcare professionals. London: Department of Health, 2009.

3. Fitzpatrick O, Biesma R, Conroy RM, McGarvey A. Prevalence and relationship between burnout and depression in our future doctors: a cross-sectional study in a cohort of preclinical and clinical medical students in Ireland. BMJ Open. 2019;9(4).

4. Njim $T$, Mbanga $C M$, Tindong $M$, Fonkou $S$, Makebe $H$, Toukam $L$, et al. Burnout as a correlate of depression among medical students in Cameroon : a cross-sectional study. BMJ Open. 2019;9(5):1-7.

5. Boni RAS, Paiva CE, de Oliveira MA, Lucchetti G, Fregnani JHTG, Paiva BSR. Burnout among medical students during the first years of undergraduate school : Prevalence and associated factors. PLoS One. 2018;13(3):1-15.

6. Silva V, Costa P, Pereira I, Faria R, Salgueira AP, Costa MJ, et al. Depression in medical students: Insights from a longitudinal study. BMC Med Educ. 2017;17(1):1-9.

7. Freudenberger HJ. Staff burnout. Journal of social issues.1974;30(1):159-65.

8. Erschens R. Professional burnout among medical students: Systematic literature review and meta-analysis.Med Teach. 2019;41(2):172-83.

9. Maslach C, Leiter MP. Understanding the burnout experience: recent research and its implications for psychiatry. World Psychiatry. 2016;15(2):103-11.

10. Schaufeli WB, Martinez IM, Pinto AM, Salanova M, Bakker AB. Burnout and engagement in university students - A cross-national study. J Cross Cult Psychol. 2002;33(5):464-81.

11. Carlotto MS, Câmara SG. Características psicométricas do Maslach Burnout Inventory - Student Survey (MBI-SS) em estudantes universitários brasileiros. PsicoUSF. 2006;11(2):167-73.

12. Halbesleben JRB, Demerout E. The construct validity of an alternative measure of burnout: Investigating the English translation of the Oldenburg Burnout Inventory. Work \& Stress. 2005;19(3):208-20.

13. Kristensen TS, Borritz M, Villadsen E, Christensen KB. The Copenhanen Burnout Inventory: A new tool for the assessment of burnout. Work \& Stress. 2005;19(3):197-207.
14. Krägeloh $C$, Henning $M$, Hawken $S$, Zhao $Y$, Shepherd D, Billington R. Validation of the WHOQOL-BREF Quality of Life Questionnaire for Use with Medical Students. Educ Heal Chang Learn Pract. 2011;24(2).

15. Costa EFO, Santos SA, Santos ATRA, Melo EV, Andrade TM. Burnout syndrome and associated factors among medical students: A crosssectional study. Clinics (São Paulo) 2012;67(6):573-80.

16. Ishak W, Nikravesh R, Lederer S, Perry R, Ogunyemi D, Bernstein C. Burnout in medical students : a systematic review. Clinic Teach; 2013;242-5.

17. Dyrbye LN, Harper W, Moutier C, Durning SJ, Power DV, Massie FS, et al. A multi-institutional study exploring the impact of positive mental health on medical student's professionalism in an era of high burnout. Acad Med. 2012;87(8):1024-31.

18. Dyrbye LN, Thomas MR, Power DV, Durning S, Moutier C, Massie Jr FS, et al. Burnout and serious thoughts of dropping out of medical school: a multiinstitutional study. Acad Med. 2010;85(1):94-102.

19. Dyrbye LN, Thomas MR, Eacker A, Harper W, Massie Jr FS, Power DV, et al. Race, ethnicity, and medical student well-being in the United States.Arch Intern Med. 2007;167(19):2103-9.

20. Dyrbye LN, Thomas MR, Massie FS, Power DV, Eacker A, Harper W, et al. Burnout and suicidal ideation among U.S. medical students. Ann Intern Med. 2008;149(5):334-41.

21. Fond G, Bourbon A, Lançon C, Boucekine M, Micoulaud-Franchi J-A, Auquier $P$, et al. Psychiatric and psychological follow-up of undergraduate and postgraduate medical students: Prevalence and associated factors. Results from the national BOURBON study. Psychiatry Res. 2019;272:425-30.

22. Bitran $M$, Zúñiga $D$, Pedrals $N$, Echeverría G, Vergara $C$, Rigotti $A$, et al. Burnout in students of health-care professions. Risk and protection fators. Rev Med Chil. 2019;147(4):510-17.

23. Ricardo YR, Paneque FRR. Hacia um estudio bidimensional del Síndrome de Burnout em estudiantes universitarios. Ciênc. Saúde coletiva. 2014;19(12):4767-75. 